\title{
Organizações Sociais da Saúde: uma expressão fenomênica da privatização da saúde no Brasil
}

\author{
Social Healthcare Organizations: a \\ phenomenological expression of \\ healthcare privatization in Brazil
}

\author{
Organizaciones Sociales de la Salud: una \\ expresión fenoménica de la privatización \\ de la salud en Brasil
}

\section{Resumo}

A pesquisa analisou o processo de expansão das Organizações Sociais da Saúde (OSS) no Brasil durante o período de 2009-2014. Para tanto, dimensionou as dez maiores OSS segundo recursos financeiros captados, explorou suas qualificações como entidades sem fins lucrativos, tomando em conta as evidências empíricas que apontam para sua expansão e consolidação no processo de gestão e prestação de serviços de saúde via estratégias próprias de organizações privadas lucrativas. $O$ estudo é descritivo e exploratório, e foi realizado com base em fontes documentais de domínio público. No plano das relações com o Estado, as OSS têm se beneficiado das brechas e facilidades concedidas pela lei e apresentado uma notável expansão. Evidenciou-se um movimento recente das OSS pela busca concomitante da condição de entidades filantrópicas, assegurando múltiplas oportunidades de captação de recursos e de benefícios fiscais; a possibilidade de aplicação de excedentes financeiros no mercado de capitais; e a remuneração de seus corpos diretivos. Há uma concentração em serviços hospitalares com maior densidade tecnológica; nítida predominância de cláusulas respeitantes ao incremento de repasses financeiros em detrimento de outras cláusulas regulatórias; existência de modalidades especiais de contratos com serviços-meios absolutamente estratégicos para o funcionamento geral do Sistema Único de Saúde. Portanto, neste estudo as OSS se configuram como um dos componentes do Complexo Econômico Industrial da Saúde, nas vertentes da gestão, da prestação e da regulação de serviços, em um cenário de intensiva mercantilização da saúde e de transferência de fundo público para o setor privado.

Organizações em Saúde; Organizações de Assistência Responsáveis; Mercantilização; Gestão em Saúde
Heloisa Maria Mendonça de Morais 1 Maria do Socorro Veloso de Albuquerque 1 Raquel Santos de Oliveira 1 Ana Karina Interaminense Cazuzu 1 Nadine Anita Fonseca da Silva 1

doi: 10.1590/0102-311X00194916

Correspondência

H. M. M. Morais

Rua Neil Armstrong 42, apto. 1702, Recife, PE 52060-170,

Brasil.

heloisa.morais@uol.com.br

1 Universidade Federal de Pernambuco, Recife, Brasil. 


\section{Introdução}

As Organizações Sociais da Saúde (OSS) começaram a surgir no Brasil na esteira das possibilidades abertas para a gestão pública após a Reforma do Estado desencadeada nos anos 1994/1995. Portanto, são consideradas como um dos padrões de apresentação do denominado "terceiro setor" e emergem como nova modalidade voltada à função social de gestão e provisão de serviços de saúde, vinculadas ao modelo das parcerias público-privadas.

Desde a sua criação, o propósito anunciado foi o de permitir e incentivar a produção não lucrativa pela sociedade de bens ou serviços públicos não exclusivos do Estado. Com efeito, a crescente absorção de atividades sociais pelo denominado "terceiro setor" tem sido uma marca recorrente em processos de Reforma do Estado nas democracias contemporâneas 1 .

Se para Bresser-Pereira, um dos principais ideólogos da Reforma, "terceiro setor" pode ser considerado uma designação adequada na medida em que sugere uma terceira forma de propriedade entre a privada e a estatal 2, deve-se registrar que esta questão está longe de ser consensual. Para ele, a Reforma deve ser entendida dentro do contexto da redefinição do papel do Estado, que deixa de ser o responsável direto pelo desenvolvimento econômico e social pela via da produção de bens e serviços, para se fortalecer na função de promotor e regulador deste desenvolvimento.

Para Violin, o termo "terceiro setor" é polêmico e muito abrangente, tendo surgido com o fortalecimento do ideário gerencial neoliberal. O IV Encontro Ibero-Americano do Terceiro Setor (1998) definiu como organizações do 'terceiro setor" aquelas que são privadas, não governamentais, sem fins lucrativos, autogovernadas, de associação voluntária 3.

Montaño, em alentado estudo sobre o "terceiro setor" 4, considera que o termo apresenta imprecisões conceituais: ao opor a concepção entre Estado e sociedade, aspecto este de clara inspiração liberal; ao expor as divergências entre os estudiosos do tema sobre quais segmentos da sociedade civil comporiam o "terceiro setor"; e ao mistificar seu caráter não governamental, autônomo e não lucrativo.

Na contra-argumentação, Montaño entende que não deve haver fragmentação entre "primeiro setor" (Estado), "segundo setor" (mercado) e "terceiro setor" (sociedade civil). Em relação aos segmentos da sociedade civil que comporiam o "terceiro setor", parece não haver consenso a respeito de quais seriam estes segmentos, se apenas as organizações formais de múltiplas naturezas (fundações empresariais, sindicatos, entidades religiosas) ou aquelas de natureza individual e informal. E por fim, o terceiro problema apontado pelo autor é seu suposto caráter não governamental, autônomo e não lucrativo. Isso porque, essas entidades estão intrinsecamente relacionadas à política de governo, quando sua sobrevivência, seu financiamento, seus projetos, sua área de abrangência, são definidos e fortemente apoiados pelas políticas governamentais. Portanto, não gozariam da autonomia que pretendem, nem prática, nem ideológica e nem financeira 4.

Desse modo, o caráter declarado de não-lucratividade das entidades do "terceiro setor" não pode esconder seus claros interesses econômicos, materializados via isenções de impostos e outros subsídios estatais, bem como a possibilidade de remunerar com altos salários seus corpos diretivos 4 .

A pesquisa entende as OSS como componentes do Complexo Econômico Industrial da Saúde (CEIS), o qual articula a geração e difusão de tecnologias, a dinâmica institucional social e a estruturação do Estado e sua relação com o setor privado. Ao definir como objeto específico o estudo de organizações que passaram a ocupar um papel destacado na prestação e na gestão de serviços de saúde - as OSS - a investigação priorizou o subsistema de serviços, um dos três subsistemas componentes do CEIS, ao lado do subsistema das indústrias de base química e biotecnológica e do subsistema de base mecânica, eletrônica e de materiais 5,6.

Nesse sentido, então, ao demonstrar a expansão e consolidação das OSS no mercado de prestação de serviços de saúde, a investigação pretendeu pôr em evidência alguns aspectos concernentes ao papel que elas desempenham no processo de privatização do sistema de saúde brasileiro, ainda que esta seja uma questão a respeito da qual persistam divergências conceituais.

Autores como Modesto entendem que as OSS não corresponderiam a um processo de privatização, por não assegurarem uma "transferência de domínio, isto é, o trespasse de um ente do domínio estatal para o dominio particular empresarial" 7 (p. 9). Diferentemente, Di Pietro 8 compreende que as parcerias entre os setores público e privado devem ser consideradas como "privatização em sentido amplo", 
envolvendo as seguintes modalidades: desregulação; desmonopolização de atividades econômicas; desnacionalização ou desestatização; delegação (concessão/permissão de serviços públicos) e contracting out, que são os acordos variados com o setor privado por meio de convênios, contratos de gestão e termos de parceria (como forma de fomento); contratos de obras; e contratos de prestação de serviços, a chamada terceirização (que é uma espécie de cooperação). Entende-se, portanto, que as OSS seriam enquadradas nessa última modalidade. Ainda numa perspectiva jurídica, a privatização seria a transformação de algo que é de regime jurídico público para o regime privado 9.

No campo da saúde, outros autores têm buscado uma compreensão para o fenômeno da privatização do setor. Para Correia \& Santos 10, a privatização acontece quando o Estado abdica de ser o próprio agente econômico produtivo e empresarial, por meio da venda das estatais ou quando renuncia de ser o executor direto de serviços públicos por intermédio de incentivos ao setor privado como fornecedores destes serviços, mediante repasses de recursos públicos ou isenção de impostos. Em poucas palavras, Scheffer 11 (p. 664) menciona que a privatização consiste na "transferência das funções e responsabilidades do setor público, completamente ou em parte, para o setor privado".

Muschell 12 vai mais além, ao definir privatização como o processo no qual atores não governamentais tornam-se progressivamente envolvidos no financiamento e/ou na provisão de serviços de saúde. O autor destaca ainda o conceito de "privatização ativa", processo pelo qual um governo desenvolve políticas que estimulam a participação privada no setor de saúde.

Pelo conjunto das formulações expostas, parte-se da hipótese de que no caso brasileiro as OSS materializariam a tendência crescente da "privatização ativa", quando o Estado estimula a formação de um mercado interno na saúde, amplia as modalidades de transferência do fundo público para o setor privado e garante os instrumentos legais para a operacionalização deste novo modelo, num contexto em que a lógica mercantil vem se tornando o elemento definidor dos rumos da política nacional de saúde.

É nessa direção que se reafirma a posição estratégica do setor de serviços no interior do CEIS como aquele de maior peso econômico, por demandar produtos dos demais segmentos desse complexo produtivo ${ }^{13}$. Por isso, Laurell 14 entende que a privatização não é uma questão técnica para o pensamento neoliberal, mas que se depreende justamente do postulado segundo o qual o mercado é o melhor meio de destinação de recursos e que suas forças somente podem entrar em movimento quando os bens se tornam mercadorias.

Apesar de, no Brasil, as OSS estarem em funcionamento há pelo menos duas décadas, suas configurações, relações com os setores da economia, assim como as articulações com novas tendências do mercado da saúde, estruturam um arranjo ainda bastante desconhecido no âmbito da gestão e da prestação de serviços. Desse modo, a pesquisa tratou de analisar a constituição das OSS, desde as entidades que as originaram e sua tradição na prestação de serviços no mercado da saúde, abordando aspectos jurídico-legais nos quais estão baseadas e a capacidade de mobilizar recursos públicos para sua expansão e financiamento.

\section{Metodologia}

Trata-se de um estudo descritivo e exploratório, fundamentado em fontes documentais e em dados secundários de domínio público. Os aspectos jurídico-legais foram levantados na legislação sobre OSS nos âmbitos federal 15 e estaduais 16,17 e na literatura jurídica sobre o tema 3,7,8. Nos sites das OSS selecionadas para a pesquisa foram coletadas informações sobre a natureza jurídica e o histórico das entidades que lhes deram origem, bem como sua expansão geográfica no Brasil.

Nos sites das secretarias estaduais de saúde de São Paulo (SES/SP) e do Rio de Janeiro (SES/RJ) e nos portais da transparência destes estados foram consultados 214 contratos de gestão e 210 termos aditivos referentes ao período de 2009 a 2014, com o objetivo de analisar o montante dos recursos financeiros mobilizados e o perfil assistencial predominante das unidades administradas pelas OSS. Além disso, consultou-se o site do jornal Valor Econômico (http://www.valor.com.br) para verificar o ranking dessas entidades no mercado empresarial. Do Instituto Brasileiro de Geografia e Estatística (IBGE) utilizou-se a Pesquisa de Assistência Médico-Sanitária de 2009 (http://www.ibge.gov.br/estado sat/temas.php?sigla $=$ sp\&tema $=$ servicossaude2009, acessado em 22/Fev/2016) e os valores do Produto Interno Bruto (PIB) do ano de 2010 para a definição da amostra de conveniência. 
Para a seleção da amostra de conveniência foram usados três critérios a serem aplicados às Unidades da Federação (UF): (i) estados com maior rede assistencial; (ii) estados com maior PIB; e (iii) como critério definitivo, estados que disponibilizavam os contratos de gestão e os termos aditivos nos sites de suas respectivas secretarias de saúde.

Pelo primeiro critério, considerando os dados da última Pesquisa de Assistência Médico-Sanitária, foram selecionados, por ordem decrescente, os estados de São Paulo, Minas Gerais, Bahia, Rio de Janeiro, Rio Grande do Sul e Paraná. Partiu-se da hipótese de que, considerando a tendência nacional de contratação de serviços pelo setor público via OSS, quanto maior a rede prestadora de serviços de saúde, maiores seriam as possibilidades de realização desta modalidade de contrato.

Pelo segundo, os estados identificados foram: São Paulo, Rio de Janeiro, Minas Gerais, Rio Grande do Sul, Paraná e Bahia. Nesse caso, a premissa orientadora da escolha dos estados foi que as OSS que movimentavam os maiores volumes de recursos financeiros deveriam estar presentes nos estados com economia mais dinâmica, portanto, com PIB mais elevados.

O terceiro critério foi decisivo, porquanto a pesquisa só poderia acontecer nos estados que disponibilizassem informações para consulta pública dos contratos de gestão e respectivos termos aditivos. Nessa condição, quando da coleta dos dados, verificou-se que apenas os estados de São Paulo (SES/ SP; http://www.transparencia.sp.gov.br, acessado em 21/Mar/2016) e Rio de Janeiro (SES/RJ. http:// www.informacaoemsaude.rj.gov.br/organizacoes-sociais-de-saude/contratos-de-gestao.html, acessado em 19/Mar/2016) haviam publicizado seus contratos com as secretarias estaduais de saúde, considerando que no Estado da Bahia os contratos de gestão não estavam disponibilizados.

Quanto aos demais estados selecionados, Paraná, Rio Grande do Sul e Minas Gerais, constatou-se que as respectivas secretarias estaduais não dispunham de contratos de gestão com as OSS. Tal constatação foi ratificada pela pesquisa Estadic - Perfil dos Estados Brasileiros 18, na qual esses estados não constavam na lista das 17 UFs que os gestores estaduais afirmavam ter contrato de gestão com OSS no ano de 2013. Por essas razões, apenas as OSS localizadas nos estados de São Paulo e Rio de Janeiro foram investigadas.

Na sequência, identificou-se a existência de 39 OSS com contratos de gestão vigentes em ambos os estados. Dentre essas, e de modo intencional, foram selecionadas as dez maiores considerando-se o valor total dos recursos financeiros declarados nos contratos de gestão e nos respectivos termos aditivos, sendo oito delas localizadas no Estado de São Paulo e duas no Estado do Rio de Janeiro.

Essa investigação é parte do projeto de pesquisa interinstitucional financiado pelo Conselho Nacional de Desenvolvimento Científico e Tecnológico (CNPq; no 405077/2013-0), intitulado Complexo Econômico Industrial da Saúde (CEIS), Inovação e Dinâmica Capitalista: Desafios Estruturais para a Construção do Sistema Universal de Saúde no Brasil. A pesquisa foi submetida à análise do Comitê de Ética em Pesquisa (CEP) da Sociedade de Ensino Superior de Vitória, Espírito Santo, e obteve parecer favorável no 1.406.975 sob o registro CAEE: 52909416.1.

\section{Resultados e discussão}

\section{Alguns aspectos jurídico-legais das OSS}

As Lei no 9.637/1998 (federal) 15, Lei Complementar no 846/1998 (Estado de São Paulo) 16 e Lei no 6.043/2011 (Estado do Rio de Janeiro) 17 qualificam como Organizações Sociais (OS) "pessoas jurídicas de direito privado, sem fins lucrativos, cujas atividades sejam dirigidas à saúde, à assistência social, ao ensino, à pesquisa e à cultura”.

A formulação e promulgação da Lei no 9.637/1998, que serviu de base para as promulgações subsequentes das leis subnacionais, teve como marco orientador a definição de OS proposta pelo Ministério da Administração Federal e Reforma do Estado (MARE), entendida como um modelo de organização pública não estatal destinado a absorver atividades "publicizáveis" mediante qualificação específica, tratando-se de uma parceria entre o Estado e a sociedade e baseada em resultados de desempenho 15.

Importa inicialmente destacar que as OS não se conformam como um novo tipo de pessoa jurídica, ou seja, esta condição significa ter apenas um título jurídico especial, conferido pelo poder público em vista do atendimento a requisitos gerais de constituição e funcionamento previstos expressamente 
em lei. O Estado permanece com o financiamento das atividades públicas, absorvidas pelas OS qualificadas para tal, e as mesmas serão responsáveis pelos resultados pactuados mediante os contratos de gestão 17 .

Entretanto, vale pontuar que no âmbito jurídico há um debate polarizado no que diz respeito ao poder discricionário do Executivo na qualificação da OS, conforme apontado em trabalho recente de Violin 3 . Segundo esse autor, e diferentemente do proposto pelo MARE e as legislações decorrentes, a decisão administrativa de conceder o título a uma OS e negar a outra, quando ambas preenchem os requisitos legais, é considerada um ato que manifestamente fere o princípio da isonomia.

Ainda, segundo as prescrições do MARE 1, as OS apresentam vantagens sobre outras formas de organizações estatais. Ao se tornarem portadoras da condição de direito privado gozariam de uma autonomia administrativa muito maior do que aquela possível dentro do aparelho do Estado, o que representaria, entre outras vantagens, a contratação de pessoal nas condições de mercado, a adoção de normas próprias para compras e contratos e a ampla flexibilidade na execução orçamentária e financeira.

Nesse sentido, nada mais oportuno do que implantar mecanismos legais que possibilitam a fuga dos preceitos constitucionais da licitação e do concurso público, os quais amarrariam a Administração Pública, e não as entidades privadas, agora qualificadas como OS 3 . Ajunte-se a essas condições a possibilidade de contratação de pessoal fora dos limites estabelecidos pela Lei de Responsabilidade Fiscal (LRF) a partir dos anos 2000. Essas condições, próprias e possíveis para o setor privado, além de se constituírem como núcleo da flexibilização, desde então assumida pela administração pública, também explicam o importante movimento de adesão ao modelo de OSS pelos gestores estaduais e municipais de saúde em todo o país 19.

Não menos importante é o fato de a Lei no 9.637/1998 15 e as subsequentes leis subnacionais, permitirem a remuneração dos dirigentes das OS, cujo valor deve ser estipulado pelo conselho administrativo destas entidades. Tal condição constitui uma vantagem, na medida em que as leis referentes às entidades privadas sem fins lucrativos anteriores à Reforma do Estado não facultavam essa possibilidade.

A propósito, no Estado de São Paulo, o contrato de gestão estipula que até $70 \%$ do valor global das despesas de custeio das respectivas unidades possam ser destinados à remuneração dos dirigentes e empregados (SES/SP; http://www.transparencia.sp.gov.br, acessado em 21/Mar/2016). Na verdade, essa condição é mais do que uma vantagem, porque ela pavimenta a rota para a apropriação privada dos recursos públicos, quer dizer, possibilita que os resultados financeiros auferidos possam configurar como geração de lucro. Sabe-se que salário não equivale a lucro. Porém, quando a produção do excedente é apropriada na forma de altos salários para os dirigentes e/ou proprietários de empresas, quaisquer que sejam elas, industriais, comerciais ou de serviços, ocorre que os salários aparecem como resultado do lucro.

Inúmeras tentativas demandadas aos Tribunais de Contas e às Secretarias de Saúde dos estados de São Paulo e do Rio de Janeiro para a obtenção de informação a respeito dos salários dos quadros dirigentes das OSS investigadas foram sempre seguidas de negativas, sob o argumento de que conforme a Lei de Acesso à Informação (LAI) são passíveis de consulta apenas os proventos de funcionários públicos, não se aplicando para empregados e dirigentes das OS. Como exceção, pode ser mencionado o caso particular, porque disponível, de algumas OSS vinculadas à Secretaria de Estado da Saúde Goiás (http://www.saude.go.gov.br/page/241/colaboradores-das-oss-e-salarios-2015-hgg, acessado em 12/Ago/2016), nas quais a remuneração dos dirigentes está publicizada, podendo ser até seis vezes maior do que aquelas de algumas categorias de nível superior.

Verificamos, ainda, outras evidências da forte associação dos recursos pagos às OSS com atividades financeiras. De acordo com o parágrafo terceiro do contrato de gestão da SES/SP, os recursos repassados aos entes contratados podem ser aplicados no mercado financeiro, devendo os resultados desta aplicação serem revertidos, exclusivamente, aos objetivos do contrato. Para efeitos desta pesquisa, contudo, não se teve acesso a informações que comprovem a ocorrência dessa reversão.

Ademais, tem-se a alteração da Lei no 846/98 16 por meio da Lei Complementar no 1.131/2010 20, a qual permitiu que as OSS pudessem utilizar até $25 \%$ da capacidade instalada dos hospitais sob sua gestão no atendimento à clientela privada, com ou sem planos e seguros de saúde. Essa Lei vigorou no período de dezembro de 2010 até maio de 2012, quando foi declarada inconstitucional pelo Tribunal de Justiça do Estado de São Paulo. 
Por fim, a constatação da ausência na Lei Federal das OS da prerrogativa de exclusividade do atendimento aos usuários do Sistema Único de Saúde (SUS), descortina o aparente sentido público do modelo ao ferir o princípio constitucional de acesso universal igualitário aos serviços 19. É inquestionável que a instituição da "dupla porta" tem historicamente privilegiado a clientela dos planos e seguros de saúde, sendo este mais um fator de aproximação das OSS com os interesses do mercado.

\section{Caracterização das OSS investigadas}

Os dados obtidos possibilitaram constatar que a primeira geração de OSS nasceu e se consolidou no Estado de São Paulo, local onde se encontram oito das dez OSS investigadas (Tabela 1). Outro aspecto marcante é o fato de oito delas terem o certificado de filantropia, quer dizer, usufruírem dos benefícios tributários referentes à concessão do Certificado de Entidade Beneficente de Assistência Social (CEBAS), particularmente a isenção de contribuições previdenciárias 21, e acumularem outros benefícios tributários próprios da condição de entidade de interesse social, além daqueles vinculados à qualificação de OSS. O principal benefício da qualificação de OS é a possibilidade de receber recursos financeiros e de administrar bens, equipamentos e pessoal do Poder Público ${ }^{3}$. Portanto, a possibilidade legal de convivência do certificado de filantropia com o título jurídico de OSS pode ser uma das explicações para a formação de grandes conglomerados destas organizações, em detrimento de outros modelos propostos dentro do "terceiro setor".

Tomando como critério a origem institucional das entidades sem fins lucrativos, posteriormente qualificadas como OSS, as dez OS investigadas foram agrupadas em três categorias (Tabela 2), quais sejam: (i) serviço social autônomo ligado a grupos empresariais; (ii) entidades privadas sem fins lucrativos de origem religiosa; e (iii) entidades privadas sem fins lucrativos de apoio a mantenedoras.

No primeiro grupo, está o Serviço Social da Construção Civil do Estado de São Paulo (Seconci-SP), serviço social autônomo ligado a grupos empresariais. Tem personalidade de direito privado, sem fins lucrativos, para prestar assistência à saúde ou ao ensino a certas categorias sociais ou a grupos profissionais, sendo mantido por doações orçamentárias públicas e privadas e por contribuições para-fiscais. Fazem parte desse grupo, por exemplo, as instituições que integram o Sistema S, como o Serviço Nacional de Aprendizagem Industrial (Senai), o Serviço Social da Indústria (Sesi), o Serviço Social do Comércio (SESC), dentre outras. À semelhança dessas instituições, o Seconci também está presente em vários estados e municípios do país.

O Seconci-SP foi fundado em 1964 por um grupo de empresários do setor para atender aos trabalhadores da construção civil e a seus familiares. Foi reconhecido como entidade filantrópica pelo Conselho Nacional de Serviço Social em 1974 e qualificado como OSS em 1998 (http://www.seconsisp.org.br, acessado em 26/Abr/2016). Convém destacar que devido aos seus múltiplos estatutos legais, o Seconci-SP pode captar recursos públicos como serviço social autônomo do Sistema S, como entidade filantrópica e, ainda, como OSS.

O segundo grupo de OSS é representado por entidades privadas religiosas de longa trajetória na área da saúde e assistência social, que têm em comum a certificação de filantropia. Para o caso da saúde, prestam serviço tanto ao setor privado quanto ao SUS. Ao analisar os processos de fundação dessas entidades pode-se identificá-los com as antigas práticas voluntárias, filantrópicas e caritativas, fundamentalmente dirigidas às populações mais carentes 4 , criadas por ordens religiosas.

Merece destaque a longa trajetória da entidade que deu origem à OSS Associação Congregação de Santa Catarina (ACSC). Sua origem remonta a Europa de fins do século XVI, quando foi declarada como Congregação das Irmãs de Santa Catarina. Chegou ao Brasil no final do século XIX e em 1922, após uma reforma de seus estatutos, passou a ser uma associação. Recebeu o CEBAS em 1967 e atualmente se considera "uma entidade filantrópica que impacta na cadeia de valor produtivo do país, com 34 casas presentes em oito estados brasileiros” (ACSC. http://www.acsc.org.br/sobre/historia/, acessado em 12/Fev/2017).

O terceiro grupo agrega as entidades privadas sem fins lucrativos de apoio a mantenedoras, que podem ser filantrópicas ou não. Estão filiadas a esse grupo: a Associação Paulista para o Desenvolvimento da Medicina (SPDM), mantenedora do Hospital São Paulo, Hospital Universitário da Universidade Federal de São Paulo; a Fundação Faculdade de Medicina (FFM), mantenedora da Faculdade de Medicina da Universidade de São Paulo e do Hospital das Clínicas; a Fundação ABC (FABC), 
Tabela 1

Classificação das Organizações Sociais da Saúde (OSS) segundo valor total dos recursos financeiros captados e desempenho destas entidades no mercado empresarial nacional. Estados de São Paulo e Rio de Janeiro, Brasil, 2009-2014.

\begin{tabular}{|c|c|c|c|c|c|c|c|c|}
\hline \multirow[t]{2}{*}{ Classificação * } & \multirow[t]{2}{*}{ oss } & \multirow[t]{2}{*}{$\begin{array}{l}\text { Contrato de } \\
\text { gestão (R\$) }\end{array}$} & \multirow[t]{2}{*}{ Termo aditivo ( $R \$$ ) } & \multirow[t]{2}{*}{ Total (R\$) } & \multicolumn{4}{|c|}{$\begin{array}{c}\text { Ranking no mercado empresarial } \\
\text { do país } \\
\text { (setor de serviços médicos) }\end{array}$} \\
\hline & & & & & 2011 & 2012 & 2013 & 2014 \\
\hline 1 & SPDM ** & $3.788 .735 .148,84$ & $1.307 .276 .036,55$ & $5.096 .011 .185,39$ & - & 171 & 168 & 167 \\
\hline 2 & Seconci-SP & $2.793 .122 .944,42$ & $1.348 .655 .452,35$ & $4.141 .778 .396,77$ & - & - & - & - \\
\hline 3 & CBSC & $2.263 .684 .312,00$ & $431.316 .109,10$ & $2.695 .000 .421,10$ & - & - & - & - \\
\hline 4 & ISCMSP & $1.398 .602 .744,20$ & $761.391 .275,49$ & 2.159.994.019,69 & 357 & 356 & - & - \\
\hline 5 & FFM & $1.154 .248 .204,00$ & $909.314 .845,00$ & $2.063 .563 .049,00$ & - & - & - & - \\
\hline 6 & Pró-Saúde *** & $1.237 .509 .193,64$ & $553.362 .513,79$ & $1.790 .871 .707,43$ & - & - & - & 325 \\
\hline 7 & LSFPD ** & $811.505 .773,04$ & $714.098 .156,64$ & $1.525 .603 .929,68$ & - & - & - & - \\
\hline 8 & HMST *** & $797.714 .410,24$ & $608.350 .530,74$ & $1.406 .064 .940,98$ & - & - & - & - \\
\hline 9 & $\operatorname{ACSC} \star \star$ & $925.242 .758,21$ & $168.707 .988,89$ & 1.093.950.747,10 & 317 & 360 & 312 & 302 \\
\hline 10 & FABC & $751.102 .474,00$ & $243.417 .757,00$ & $994.520 .231,00$ & - & - & - & \\
\hline Total & & $15.921 .467 .962,59$ & $7.045 .890 .665,55$ & $22.967 .358 .628,14$ & & & & \\
\hline
\end{tabular}

ACSC: Associação Congregação de Santa Catarina; CBSC: Cruzada Bandeirante São Camilo Assistência Médico-Social; FABC: Fundação ABC; FFM: Fundação Faculdade de Medicina; HMST: Hospital Maternidade Santa Terezinha; ISCMSP: Irmandade Santa Casa de Misericórdia de São Paulo; LSFPD: Lar São Francisco da Providência de Deus; Pró-Saúde: Associação Beneficente de Assistência Médica e Hospitalar; Seconci-SP: Serviço Social da Construção Civil do Estado de São Paulo; SPDM: Associação Paulista para o Desenvolvimento da Medicina.

Fonte: contratos de gestão disponíveis nos sites da Secretaria de Estado de Saúde do Rio de Janeiro (http://www.informacaoemsaude.rj.gov.br/ organizacoes-sociais-de-saude/contratos-de-gestao.html), no Portal da Transparência do Estado de São Paulo (http://www.transparencia.sp.gov.br) e no site da revista Valor Econômico (http://www.valor.com.br).

* Classificação em ordem de grandeza e segundo o valor total dos recursos financeiros declarados nos contratos de gestão e nos respectivos termos aditivos, 2009-2014;

** Essas entidades têm contrato de gestão com os estados de São Paulo e Rio de Janeiro;

*** Essas entidades têm contratos apenas com o Estado do Rio de Janeiro, iniciados no ano de 2012.

mantenedora da Faculdade de Medicina do Grande ABC; o Hospital Maternidade Santa Terezinha (HMST), mantenedor da Faculdade de Ciências Médicas e da Saúde de Juiz de Fora - Suprema. Deve ser ressaltada a importante penetração desse conjunto de OSS no ensino, para o que tem concorrido, sobretudo na última década, o financiamento público.

\section{Financiamento, expansão geográfica e perfil assistencial das OSS}

Na Tabela 1, pode-se observar que no período de 2009 a 2014 as dez maiores OSS do país mobilizaram um montante de R\$22.967.358.628,14, considerando-se os valores declarados nos contratos de gestão e nos termos aditivos estabelecidos entre essas organizações e as secretarias estaduais de saúde dos estados de São Paulo e do Rio de Janeiro.

Ao se analisar esse montante, verifica-se que há uma diferença cinco vezes maior entre os valores recebidos pela SPDM e pela FABC. Não por acaso, a SPDM, mantenedora do Hospital São Paulo, aparece nas posições 171ạ, 168a e 167ạ entre as 1.000 maiores empresas de diversos setores produtivos do país, nos anos 2012, 2013 e 2014, respectivamente (segundo o jornal Valor Econômico; http://www. valor.com.br).

Nesse contexto, em 2014, considerando apenas o ranking do setor de serviços médicos, a SPDM ocupava o 2o lugar marcando uma importante presença na prestação da assistência em diversos outros estados, prestação esta que envolvia 37.500 trabalhadores (Figura 1). Ainda assim, ela se autodenomina a "maior entidade filantrópica de prestação de serviços de saúde do Brasil sem fins lucrativos" (Associação Paulista para o Desenvolvimento da Medicina. https://www.spdm.org.br, acessado em 
Tabela 2

Caracterização das Organizações Sociais da Saúde (OSS) dos estados de São Paulo e do Rio de Janeiro, Brasil, segundo a origem institucional.

\begin{tabular}{|c|c|c|c|c|}
\hline Classificação * & OSS & Ano de criação & Ano de qualificação & Caracterização \\
\hline 1 & SPDM & 1933 & 1998 & $\begin{array}{c}\text { Entidade privada de fins não lucrativos de apoio a } \\
\text { mantenedoras (filantrópica) }\end{array}$ \\
\hline 2 & Seconci-SP & 1964 & 1998 & $\begin{array}{c}\text { Serviço social autônomo ligado a grupo empresarial } \\
\text { (filantrópica) }\end{array}$ \\
\hline 3 & CBSC & 1949 & 2008 & Entidade privada religiosa de fins não lucrativos (filantrópica) \\
\hline 4 & ISCMSP & 1560 & 1999 & Entidade privada religiosa de fins não lucrativos (filantrópica) \\
\hline 5 & FFM & 1986 & 2008 & $\begin{array}{l}\text { Entidade privada de fins não lucrativos de apoio a } \\
\qquad \text { mantenedoras }\end{array}$ \\
\hline 6 & Pró-Saúde & 1967 & 2012 & Entidade privada religiosa de fins não lucrativos (filantrópica) \\
\hline 7 & LSFPD & 1986 & 2007 & Entidade privada religiosa de fins não lucrativos (filantrópica) \\
\hline 8 & HMST & 1926 & 2012 & $\begin{array}{l}\text { Entidade privada de fins não lucrativos de apoio a } \\
\text { mantenedoras }\end{array}$ \\
\hline 9 & ACSC & 1992 & 1998 & Entidade privada religiosa de fins não lucrativos (filantrópica) \\
\hline 10 & FABC & 1967 & 2006 & $\begin{array}{l}\text { Entidade privada de fins não lucrativos de apoio de } \\
\text { mantenedoras (filantrópica) }\end{array}$ \\
\hline
\end{tabular}

ACSC: Associação Congregação de Santa Catarina; CBSC: Cruzada Bandeirante São Camilo Assistência Médico-Social; FABC: Fundação ABC;

FFM: Fundação Faculdade de Medicina; HMST: Hospital Maternidade Santa Terezinha; ISCMSP: Irmandade Santa Casa de Misericórdia de São Paulo; LSFPD: Lar São Francisco da Providência de Deus; Pró-Saúde: Associação Beneficente de Assistência Médica e Hospitalar; Seconci-SP: Serviço Social da Construção Civil do Estado de São Paulo; SPDM: Associação Paulista para o Desenvolvimento da Medicina.

Fonte: sites oficiais das entidades, da Secretaria de Estado de Saúde do Rio de Janeiro (http://www.informacaoemsaude.rj.gov.br/organizacoes-sociaisde-saude/contratos-de-gestao.html) e do Portal da Transparência do Estado de São Paulo (http://www.transparencia.sp.gov.br).

* Classificação em ordem de grandeza e segundo o valor total dos recursos financeiros declarados nos contratos de gestão e nos respectivos termos aditivos, 2009-2014.

03/Mar/2016). Convém ainda considerar que a presença destacada no mercado empresarial não se restringe às OSS mais antigas, desde que a Pró-Saúde - que foi qualificada em 2012 no Estado do Rio de Janeiro - ocupou a 325o posição entre as 1.000 maiores empresas do país, no ano de 2014 (Tabela 1). Já no setor de serviços médicos, ela ocupa a 8a posição entre as 10 maiores empresas (segundo o jornal Valor Econômico; http://www.valor.com.br). É notável que uma entidade desse porte e que afirma ter "a maior equipe de administradores hospitalares do Brasil nos setores público, filantrópico e privado" tenha se estabelecido no mercado com base na condição de entidade filantrópica (Associação Beneficente de Assistência Médica e Hospitalar. http://www.prosaude.org.br/inst.asp/1, acessado em 15/ Mar/2016).

Um importante achado desta investigação é o fato de os termos aditivos de cada contrato de gestão virem progressivamente se tornando um instrumento adicional de captação de recursos para as OSS, porquanto se observou que seus valores podem variar entre $18,2 \%$ e $87,9 \%$ do montante do valor inicial dos respectivos contratos de gestão (Tabela 1). A propósito, chama a atenção que os objetos dos referidos termos versem, sobretudo, sobre a prorrogação do prazo contratual e orçamento de custeio; a repactuação do valor referente ao custeio; o repasse adicional de recursos financeiros para o reequilíbrio econômico-financeiro; o repasse de recursos de investimentos visando à aquisição de equipamentos, observando-se nítida predominância de cláusulas respeitantes ao incremento de repasses financeiros para essas entidades. Em raras situações, os termos aditivos tratam da redução de recursos financeiros de custeio por descumprimento de metas.

Já a Figura 1, apresenta a expansão geográfica das dez maiores OSS presentes em 17 estados do país, as quais têm contratos de gestão com as secretarias de saúde estaduais e com algumas secretarias municipais. Essa expansão revela a existência de uma notável concentração dessas organizações no eixo Sul-Sudeste, o que está relacionado ao dinamismo econômico regional. Segundo dados do IBGE (http://censo2010.ibge.gov.br, acessado em 26/Abr/2016), os estados do Sudeste produziram 


\section{Figura 1}

Distribuição geográfica nas Unidades da Federação das dez Organizações Sociais da Saúde (OSS) investigadas. Brasil, 2016.

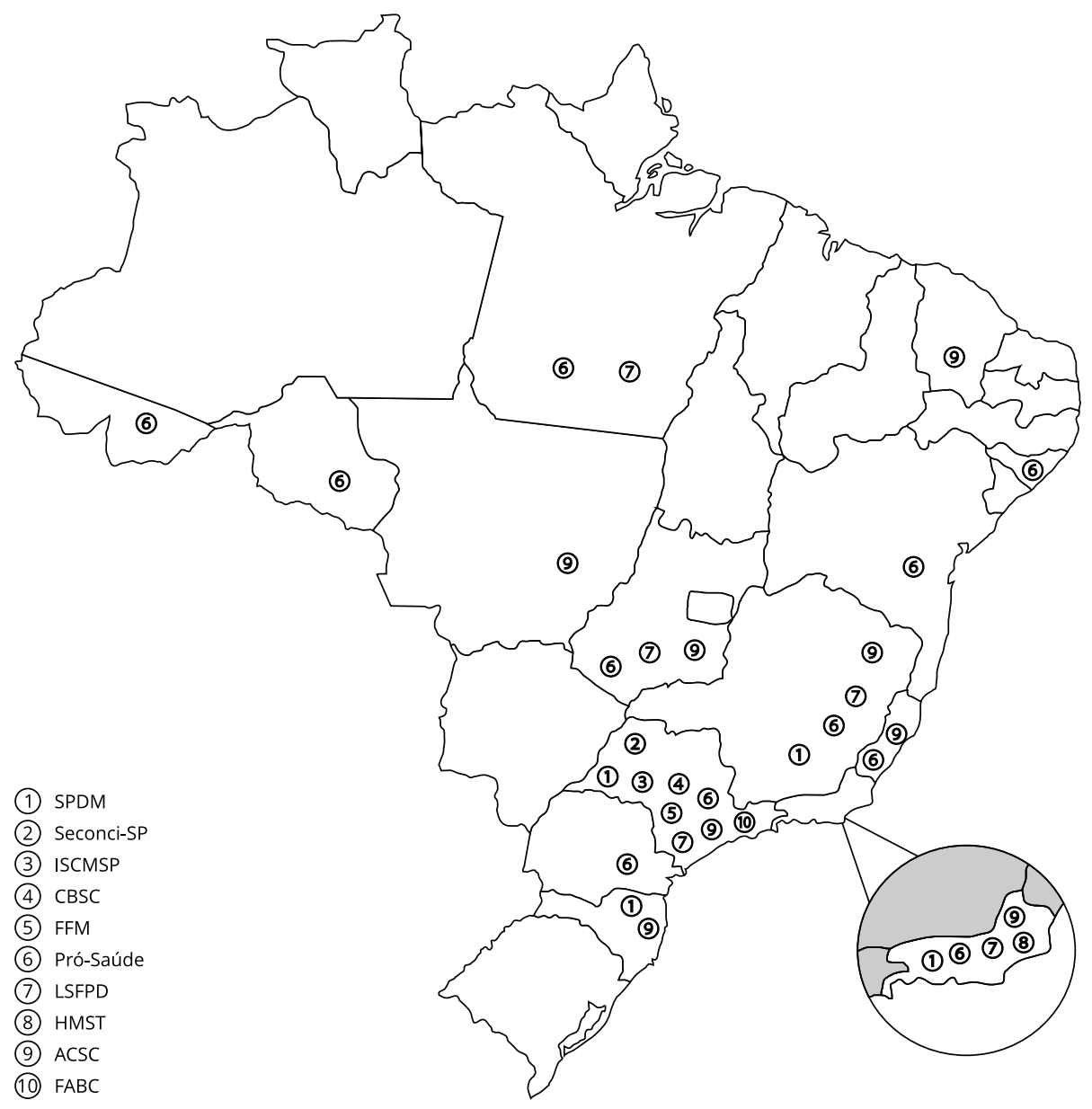

ACSC: Associação Congregação de Santa Catarina; CBSC: Cruzada Bandeirante São Camilo Assistência Médico-Social; FABC: Fundação ABC FFM: Fundação Faculdade de Medicina; HMST: Hospital Maternidade Santa Terezinha; ISCMSP: Irmandade Santa Casa de Misericórdia de São Paulo; LSFPD: Lar São Francisco da Providência de Deus; Pró-Saúde: Associação Beneficente de Assistência Médica e Hospitalar; Seconci-SP: Serviço Social da Construção Civil do Estado de São Paulo; SPDM: Associação Paulista para o Desenvolvimento da Medicina.

precisamente 55,4\% das riquezas brasileiras, e o Estado de São Paulo é responsável pela maior participação percentual no PIB, sendo este valor três vezes maior do que o do segundo colocado, o Rio de Janeiro. Chama a atenção a capacidade dessas dez maiores OSS de se expandirem pelo território nacional, alcançando localidades contíguas ou mesmo outras situadas mais à distância, configurando um movimento de expansão que sugere a formação de monopólios.

A expansão geográfica das dez maiores OSS, como mostra a Figura 1, sugere que os dados referentes ao volume de recursos financeiros captados por essas organizações (Tabela 1) podem estar subestimados, considerando que foi possível acessar apenas os contratos de gestão e os termos aditivos nos sites das secretarias estaduais de São Paulo e do Rio de Janeiro.

A propósito, em estudo recentemente publicado, entre 53 entes federativos (estados e capitais), o Estado do Rio de Janeiro aparece no 35o lugar no Índice Geral de Transparência Ativa, além de ficar evidente que muitos entes federativos ainda não cumprem o disposto na Lei no 12.527/2011. Essa 
ausência de publicização de parte dos contratos de gestão e dos termos aditivos, assim como de outros documentos, a citar a obrigatoriedade de publicação anual dos relatórios financeiros e do relatório de execução do contrato de gestão, revela um fenômeno de inquestionável importância, qual seja, a não transparência dos atos praticados, o que dificulta em muito a regulação pública das OSS 22,23,24,25.

Em relação ao perfil assistencial dos estabelecimentos gerenciados pelas OSS com contratos de gestão nas esferas estaduais e municipais em São Paulo e no Rio de Janeiro, a exceção daqueles administrados pela SPDM - a qual se destaca pela ampla diversidade de serviços prestados, sejam hospitais e ambulatórios gerais e especializados ou unidades de atenção básica e de saúde mental - observou-se uma concentração em serviços hospitalares, equivalendo a um total de 55 contratos com hospitais gerais e 19 com hospitais de especialidades.

A esse respeito, o estudo de Rodrigues et al. 26 apontou que no Estado de São Paulo o grupo dos hospitais gerais (69\% do total da rede hospitalar) concentrava os maiores orçamentos das OSS e, no total, as instituições que elas gerenciavam tinham orçamento $18 \%$ maior do que as unidades da administração direta. Dados da SES/SP (http://www.transparencia.sp.gov.br, acessado em 21/ Mar/2016) e do IBGE (http://www.ibge.gov.br/estadosat/temas.php?sigla=sp\&tema=servicossau de2009, acessado em 22/Fev/2016) informavam que, em 2009, as OSS paulistas gerenciavam 22\% dos estabelecimentos públicos de saúde, de um total de 181 serviços. Já em 2016, esse percentual passou a ser de 58\%, de um total de 191 serviços, o que representou um aumento de $175 \%$ (SES/SP; http:// www.transparencia.sp.gov.br, acessado em 21/Mar/2016; http://www.fiesp.com.br/indices-pesqui sas-e-publicacoes/saude-publica-do-estado-de-sao-paulo/).

Merece um destaque particular os objetos constantes de dois contratos da SES/SP com a Seconci -SP, os quais dizem respeito à gestão da Central de Regulação de Oferta de Serviços de Saúde (CROSS) e do Centro Estadual de Armazenamento e Distribuição de Insumos de Saúde (CEADIS). Ou seja, no caso da Seconci-SP, o estado transfere para uma OSS - com a qual ele próprio tem contratos de gestão para o gerenciamento de hospitais e ambulatórios gerais e especializados, e de serviços de apoio diagnóstico e terapêutico - autonomia para tratar de toda a oferta e demanda de leitos na rede estadual. Ora, essa não é uma atividade isenta de interesses, porquanto são diferenciados os gastos e as taxas de lucratividade por grupos de leitos específicos, seja em procedimentos de alta ou de média complexidade.

Em relação à gestão do CEADIS, deve-se ressaltar ser este um setor altamente estratégico, pois que destinado ao abastecimento da totalidade dos serviços de saúde do estado. O que, por suposto, presumiria uma relação de absoluta confiança entre o ente contratante e o ente gestor, além de requerer uma regulação interna pautada em normas muito rigorosas.

Demonstradas todas essas especificidades pertinentes às OSS, estão dadas as condições que justificam o argumento inicial segundo o qual essas entidades, ao mediarem interesses públicos e privados no âmbito do mercado da saúde, têm concorrido para a tendência geral do sistema, qual seja, sua privatização.

\section{Considerações finais}

Os resultados da pesquisa põem em xeque a natureza não lucrativa das OSS como entidades do "terceiro setor", cabendo indagar por que em uma sociedade de mercado essas entidades estariam motivadas tão-somente pelos valores da filantropia, da solidariedade social ou do interesse público.

Afinal, a autorização em lei para o pagamento de salários aos dirigentes das OSS, a figuração dessas entidades em ranking das maiores empresas do país e a possibilidade de aplicação dos excedentes monetários na dinâmica da financeirização dos capitais, somente poderiam ser explicadas entendendo-se as organizações como forma política ancorada na dinâmica de expansão do mercado da saúde e na acumulação decorrente deste processo.

Assim, o papel conferido à sociedade civil toma forma cada vez mais em iniciativas privadas que se colocam como complementares ao papel do Estado, mas de um modo em que a provisão e a gestão de serviços ocorrem sob nítida dependência da esfera governamental. Nessa direção, foi possível observar que as organizações privadas ditas de interesse público - neste caso, as OSS - carecem de expressivas e permanentes transferências do fundo público para seu financiamento, expansão e consolidação. 
Em um sistema público de saúde como o SUS, no qual há um déficit de investimento quase incomensurável e cuja sobrevivência técnica e política permanece altamente dependente do setor privado, dá-se que as trocas mercantis estão imbricadas em todas as relações mantidas entre seus componentes público e privado.

Quer dizer, ao mesmo tempo em que as OSS se afirmam por estratégias as mais atuais e incitantes do sistema do capital, estratégias de fazer o dinheiro se valorizar e de criar valor, elas tornam a referendar antigas práticas que vão distanciando o sistema de saúde brasileiro de sua condição de público e democrático.

Por fim, o que acaba de ser apresentado pode constituir uma adequada explicação para a crescente expansão das OSS no Brasil, nas últimas duas décadas. E não como um fenômeno aparente, desvinculado dos interesses gerais da sociedade, mas como uma realidade determinada por, e determinante de, muitos outros movimentos, internos e externos ao setor saúde, todos eles articulados pela superestrutura que dirige e governa o modelo econômico em vigência. É nesse sentido, então, que as OSS devem ser entendidas como um dos componentes do CEIS, nas vertentes da gestão, da prestação e da regulação de serviços, em um cenário de intensiva mercantilização do setor saúde.

\section{Colaboradores}

H. M. M. Morais formulou o estudo, contribuiu na análise dos dados, na discussão dos resultados e revisou a versão final. M. S. V. Albuquerque e R. S. Oliveira contribuíram na análise dos dados, na redação do artigo e participou da revisão final. A. K. I. Cazuzu e N. A. F. Silva contribuíram com a coleta dos dados, bem como na análise e discussão.

\section{Agradecimentos}

As autoras agradecem aos pesquisadores do grupo das OSS da Faculdade de Direito de Vitória e da Universidade Federal do Espírito Santo e aos professores Lígia Bahia e Mario Dal Poz, coordenadores do projeto Complexo Econômico Industrial da Saúde, Inovação e Dinâmica Capitalista: Desafios Estruturais para a Construção do Sistema Universal de Saúde no Brasil, pelas discussões que empreenderam coletivamente. Ao CNPq (processo no 405077/2013-0) pelo financiamento.

\section{Referências}

1. Secretaria da Reforma do Estado, Ministério da Administração Federal e Reforma do Estado. Organizações sociais. Brasília: Ministério da Administração e Reforma do Estado; 1997. (Cadernos MARE da Reforma do Estado, 2).

2. Bresser-Pereira LC, Grau NC. Entre o Estado e o mercado: o público não-estatal. In: BresserPereira LC, Grau NC, organizadores. O público não-estatal na reforma do Estado. Rio de Janeiro: Editora FGV; 1999. p. 15-48.

3. Violin TC. Terceiro setor e as parcerias com a administração pública: uma análise crítica. 3a Ed. Belo Horizonte: Fórum; 2015.

4. Montaño C. Terceiro setor e questão social: crítica ao padrão emergente de intervenção estatal. São Paulo: Cortez Editora; 2001.

5. Gadelha CAG. O complexo industrial da saúde e a necessidade de um enfoque dinâmico na economia da saúde. Ciênc Saúde Coletiva 2003; 8:521-35. 
6. Gadelha CAG, Barbosa R, Maldonado J, Vargas M, Costa L. Saúde e desenvolvimento. Informe CEIS 2011; (2):1-13.

7. Modesto PEG. Reforma administrativa e marco legal das organizações sociais no Brasil: as dúvidas dos juristas sobre o modelo das organizações sociais. Revista do Serviço Público 1997; 48:1-27.

8. Di Pietro MSZ. Parcerias na administração pública. 4a Ed. São Paulo: Editora Atlas; 2004.

9. Araújo EN. Curso de Direito Administrativo. São Paulo: Editora Saraiva; 2005.

10. Correia MV, Santos VM. Privatização da saúde via novos modelos de gestão: as Organizações Sociais em questão. In: Bravo MIS, Andreazzi MFS, Menezes JSB, Lima JB, Souza RO, organizadoras. A mercantilização da saúde em debate: as organizações sociais no Rio de Janeiro. Rio de Janeiro: Universidade do Estado do Rio de Janeiro/Rede Sirius; 2015. p. 33-9.

11. Scheffer M. O capital estrangeiro e a privatização do sistema de saúde brasileiro. Cad Saúde Pública 2015; 31:663-6.

12. Muschell J. Privatization in health. Health economics technical briefing note. Geneva: World Health Organization; 1995.

13. Costa LS, Gadelha CAG, Maldonado J, Vargas M, Quental C. Análise do subsistema de serviços em saúde na dinâmica do complexo econômico-industrial da saúde. In: Fundação Oswaldo Cruz, organizador. A saúde no Brasil em 2030: prospecção estratégica do sistema de saúde brasileiro: desenvolvimento produtivo e complexo da saúde. Rio de Janeiro: Fundação Oswaldo Cruz/Instituto de Pesquisa Econômica Aplicada/Ministério da Saúde/Secretaria de Assuntos Estratégicos da Presidência da República; 2013. p. 121-59. (Desenvolvimento Produtivo e Complexo da Saúde, 5).

14. Laurell AC. La lógica de la privatización en salud. In: Eibenschutz C, organizador. Política de saúde: o público e o privado. Rio de Janeiro: Editora Fiocruz; 1996. p. 31-48.

15. Brasil. Lei no 9.637, de 15 de maio de 1998. Dispõe sobre a qualificação de entidades como organizações sociais, a criação do Programa Nacional de Publicização, a extinção dos órgãos e entidades que menciona e a absorção de suas atividades por organizações sociais, e dá outras providências. Diário Oficial da União 1998; 18 mai.

16. São Paulo. Lei Complementar no 846 , de 4 de junho de 1998. Dispõe sobre a qualificação de entidades como organizações sociais e dá outras providências. Diário Oficial - Executivo 1998; 5 jun.
17. Rio de Janeiro. Lei no 6.043, de 19 de setembro de 2011. Dispõe sobre a qualificação de entidades sem fins lucrativos como organizações sociais, no âmbito da saúde, mediante contrato de gestão, e dá outras providências. Diário Oficial do Estado do Rio de Janeiro 2011; 19 set.

18. Instituto Brasileiro de Geografia e Estatística. Pesquisa de Informações Básicas Estaduais. Perfil dos estados brasileiros, 2013. Rio Janeiro: Instituto Brasileiro de Geografia e Estatística; 2014.

19. Silva VM, Lima SML, Teixeira M. Organizações Sociais e Fundações Estatais de Direito Privado no Sistema Único de Saúde: relação entre público e o privado e mecanismos de controle social. Saúde Debate 2015; 39:145-54.

20. São Paulo. Lei Complementar no 1.131, de 27 de dezembro de 2010. Altera a Lei Complementar n. 846, de 1998, que dispõe sobre a qualificação de entidades como organizações sociais. Diário Oficial - Executivo 2010; 28 dez.

21. Barroso HM, Fernandes IR. Mantenedoras educacionais privadas: histórico, organização e situação jurídica. Rio de Janeiro: Observatório Universitário; 2007. (Documento de Trabalho, 67).

22. Michener G. Transparência local no Brasil: avaliando a aplicação da lei de acesso nos estados e nas grandes cidades. http://transpa rencia.ebape.fgv.br/sites/transparencia.ebape. fgv.br/files/fgv_relatorio_transparencia_cida des_v3.pdf (acessado em 28/Out/2016).

23. Contreiras H, Matta GC. Privatização da gestão do sistema municipal de saúde por meio de Organizações Sociais na cidade de São Paulo, Brasil: caracterização e análise da regulação. Cad Saúde Pública 2015; 31:285-97.

24. Silva VC, Barbosa PR, Hortale VA. Parcerias na saúde: as Organizações Sociais como limites e possibilidades na gerência da Estratégia Saúde da Família. Ciênc Saúde Coletiva 2016; 21:1365-76.

25. Pacheco HF, Gurgel Júnior GD, Santos FAS, Ferreira SCC, Leal EMM. Organizações sociais como modelo de gestão da assistência à saúde em Pernambuco, Brasil: percepção de gestores. Interface (Botucatu) 2016; 20:585-95.

26. Rodrigues RC, Olímpio JN, Viana B, Magalhães A, Mendes JDV. Rede hospitalar estadual: resultados da administração direta e das organizações sociais. RAS 2014; 16:111-22. 


\section{Abstract}

The study analyzed the expansion of Social Healthcare Organizations (OSS in Portuguese) in Brazil from 2009 to 2014. The ten largest OSS were measured according to their budget funding and their qualifications as non-profit organizations were explored, considering evidence of their expansion and consolidation in the management and provision of health services via strategies proper to for-profit private enterprises. The study is descriptive and exploratory and was based on public-domain documents. In their relations with government, the OSS have benefited from legal loopholes and incentives and have expanded accordingly. There has been a recent trend for these organizations to simultaneously apply for status as charitable organizations, thereby ensuring multiple opportunities for fundraising and additional tax incentives, permission to invest financial surpluses in the capital market, and remunerate their boards of directors. These organizations tend to concentrate in technology-dense hospital services, with clauses concerning increasing financial transfers to the detriment of other regulatory clauses, and special contract modalities for enabling services that are absolutely strategic for the overall functioning of the Brazilian Unified National Health System. Thus, in this study, the OSS are one component of the Health Economic and Industrial Complex, acting in management, provision, and regulation of services in a scenario of intensive commodification of health and the transfer of public funds to the private sector.

Health Organizations; Accountable Care Organizations; Commodification; Health Management

\section{Resumen}

La investigación analizó el proceso de expansión de las Organizaciones Sociales de Salud (OSS) en Brasil, durante el período de 2009-2014. Para ello, se dimensionaron las diez mayores OSS, según los recursos financieros captados, exploró sus características, como entidades sin ánimo de lucro, tomando en consideración las evidencias empíricas que apuntan a su expansión y consolidación en el proceso de gestión y prestación de servicios de salud, vía estrategias propias de organizaciones privadas con ánimo de lucro. El estudio es descriptivo $y$ exploratorio, y fue realizado en base a fuentes documentales de dominio público. En el plano de las relaciones con el Estado, las OSS se han beneficiado de las brechas y facilidades concedidas por la ley y presentado una notable expansión. Se evidenció un movimiento reciente de esas organizaciones por la búsqueda concomitante de su condición como entidades filantrópicas, asegurando múltiples oportunidades de captación de recursos y de beneficios fiscales; la posibilidad de inversión de excedentes financieros en el mercado de capitales; y la remuneración de sus cuerpos directivos. Existe una concentración en servicios hospitalarios con una mayor densidad tecnológica; nítida predominancia de cláusulas, respecto al incremento de transferencias financieras, en detrimento de otras cláusulas regulatorias; existencia de modalidades especiales de contratos con servicios-medios absolutamente estratégicos para el funcionamiento general del Sistema Unico de Salud. Por tanto, en este estudio las OSS se configuran como uno de los componentes del Complejo Económico Industrial de la Salud, en las vertientes de la gestión, de la prestación y de la regulación de servicios, en un escenario de intensiva mercantilización de la salud y de transferencia de fondos públicos hacia el sector privado.

Organizaciones en Salud; Organizaciones Responsables por la Atención; Mercantilización; Gestión en Salud
Recebido em 11/Nov/2016

Versão final reapresentada em 12/Mai/2017

Aprovado em 01/Jun/2017 